Article

\title{
Structural Diversity of Streptococcal Mutans Synthesized under Different Culture and Environmental Conditions and Its Effect on Mutanase Synthesis
}

\author{
Adrian Wiater *, Małgorzata Pleszczyńska, Katarzyna Próchniak and Janusz Szczodrak \\ Department of Industrial Microbiology, Maria Curie-Skłodowska University, Akademicka 19, \\ 20-033 Lublin, Poland; E-Mails: mplesz@poczta.onet.pl (M.P.); kasiaproch@poczta.onet.pl (K.P.); \\ szczo@poczta.umcs.lublin.pl (J.S.) \\ * Author to whom correspondence should be addressed; E-Mail: adrianw2@wp.pl; \\ Tel./Fax: +48-81-537-5960.
}

Received: 14 August 2012; in revised form: 27 September 2012 / Accepted: 28 September 2012 / Published: 9 October 2012

\begin{abstract}
Streptococcal mutans synthesized under different conditions by growing cultures or by their glucosyltransferases were shown to exhibit a great structural and property diversity. Culturing and environmental factors causing structural differences in mutans were specified. All of the obtained biopolymers (76 samples) were water-insoluble and most of them (72) had a structure with a predominance of $\alpha-(1 \rightarrow 3)$-linked glucose (i.e., the content of $\alpha-(1 \rightarrow 3)$-linkages in the glucan was always higher than $50 \%$, but did not exceed $76 \%)$. An exception were four glucans containing more than $50 \%$ of $\alpha-(1 \rightarrow 6)$ sequences. In these structurally unique mutans, the ratio of $\alpha-(1 \rightarrow 3)-$ to $\alpha-(1 \rightarrow 6)$-bonds ranged from 0.75 to 0.97 . Aside from one polymer, all others had a heavily branched structures and differed in the number of $\alpha-(1 \rightarrow 3), \alpha-(1 \rightarrow 6)$, and $\alpha-(1 \rightarrow 3,6)$ linkages and their mutual proportion. The induction of mutanase production in shaken flask cultures of Trichoderma harzianum by the structurally diverse mutans resulted in enzyme activities ranging from 0.144 to $1.051 \mathrm{U} / \mathrm{mL}$. No statistical correlation was found between the total percentage content of $\alpha$-( $1 \rightarrow 3)$-linkages in the $\alpha$-glucan and mutanase activity. Thus, despite biosynthetic differences causing structural variation in the mutans, it did not matter which mutan structures were used to induce mutanase production.
\end{abstract}

Keywords: mutan; glucosyltransferase; cariogenic streptococci; NMR spectroscopy 


\section{Introduction}

Mutans, i.e., mixed-linkage $[\alpha-(1 \rightarrow 3), \alpha-(1 \rightarrow 6)]$ water-insoluble D-glucans, are structural and functional components of cariogenic biofilms and are commonly used as specific and efficient inducers of mutan-degrading enzymes known as mutanases - $\alpha-(1 \rightarrow 3)$-glucan 3-glucanohydrolases [1]. Mutans are synthesized from sucrose by the action of one or more constitutive glucosyltransferases (Gtfs) secreted by mutans streptococci (mainly Streptococcus mutans and S. sobrinus). Each enzyme has distinctive properties, varying in its requirement for a primer molecule, the proportion of $\alpha-(1 \rightarrow 3)-$ and $\alpha$ - $(1 \rightarrow 6)$-linkages, the degree of branching it introduces into the glucan, and the total length of the glucan chain produced. Thus, the overall properties of a mutan depend on the relative activity of different Gtfs and also on their dynamic interactions, since one Gtf may modify the product of another [2-4]. Consequently, mutans have a highly branched and diverse structure in which $\alpha-(1 \rightarrow 3)$-glucosidic bonds predominate.

One of the methods of preventing dental caries is to destroy the mutan framework of dental plaque using mutanases synthesized by various bacteria and filamentous fungi $[5,6]$. However, streptococcal synthesis of mutan for the specific induction and extracellular secretion of mutanase in microbial cultures has only been carried out on a small laboratory scale, and this type of glucan has not yet been made available as a commercial product [7]. Thus, the investigation of the structural diversity of mutans synthesized under changing culture and environmental conditions and the estimation of the effect of these diverse inducers on mutanase activity would facilitate the production of this valuable enzyme.

Although there are many reports on the linkage analysis of mutans [8-10] and their enzymatic degradation [11], most of these studies have been performed on glucans synthesized by isolated and highly purified Gtfs [12-14]. Structural information on mutans formed by crude Gtf preparations is sparse $[15,16]$. On the other hand, data from in vitro studies using individual Gtfs indicate that the polymers thus synthesized possess a distinct structure and properties than the products formed by a mixture of Gtfs or a crude enzyme preparation [13,17,18]. In others words, separate enzymes do not mimic the Gtf interactions present in a Gtf mixture, which could modify the final polymer. Therefore, in the present study mutans were produced using non-purified enzymatic preparations containing Gtf complexes which, as showed by Guggenheim [15], Ebisu and Misaki [19], as well as Inoue and co-workers [17], lead to obtaining natural products more resistant to enzymatic digestion, and synthesized in the absence of primer dextran.

There are many papers on the structure and function of streptococcal mutans $[1,3,16]$, but only a few of them discuss the high degree of structural heterogeneity of these biopolymers synthesized in vitro by Gtfs under different environmental conditions [20-22]. It should also be noted that the precise causes of the great diversity of water-insoluble $\alpha$-(1 $\rightarrow 3)$-glucans have not been thoroughly investigated. Moreover, we know of no work on the effect of the diverse structure of the mutans used in microbial cultures as mutanase inducers on the enzymatic activity of this catalyst. Accordingly, the aim of these investigations was to show structural variations in streptococcal mutans caused by their synthesis under different culture and environmental conditions, and to study the influence of structurally diverse biopolymers on the induction of synthesis of T. harzianum mutanase. 


\section{Results and Discussion}

The production of mutan by cariogenic streptococci involves two separate stages: synthesis and secretion of Gtfs into the culture medium and formation of glucan from sucrose by the same enzymes present in the post-culture supernatant. In a previous study, a detailed chemical structure of a mutan synthesized by cariogenic streptococci was analyzed, and the best operating conditions for efficient production of this polymer were standardized [7,16]. Here, it was assumed that each deviation from optimal conditions estimated for both stages of mutan production can modify the mutual proportions of the different types of links in the polymer leading to a high structural diversity of the glucans obtained in this way. Therefore, the type and the proportions of the main linkages in the mutan macromolecule formed under different culturing and environmental conditions were studied. These conditions were determined using various operating factors with a relatively wide range of action on the individual stages of mutan biosynthesis.

\subsection{Structure and Some Properties of Mutans Synthesized by Cariogenic Streptococci Grown under Different Culture Conditions}

The data summarized in Table 1 clearly indicate that the percentage content of the different types of linkages (calculated from an integration of the anomeric proton signal areas as shown in Figure 1) in the mutan macromolecule and their mutual proportions varied widely and depended on the strain of cariogenic bacteria used to produce Gtfs and the type of medium utilized for the cultivation of mutans streptococci. However, no direct correlations between mutan structure and conditions of mutan production were found. Among the four cariogenic streptococci, the strain S. sobrinus/downei 21020 and, in most cases, the media I, BHI, TTY, and THB were the best for the production of mutans with the highest content of $\alpha-(1 \rightarrow 3)$-linkages and the highest proportion of $(1 \rightarrow 3)$ - to $(1 \rightarrow 6)$-linkages. Experimental results reported earlier by Nisizawa et al. [23] also show some strain-dependent differences in the linkage structure of water-insoluble glucans (IG-1) formed by 12 various cultures of $S$. mutans cultivated in a sucrose-containing medium. The content of $\alpha-(1 \rightarrow 3)$ - and $\alpha-(1 \rightarrow 6)$-linkages in polysaccharide preparations produced by the individual strains of oral streptococci in that study ranged from $49 \%$ to $64 \%$ and from $31.5 \%$ to $49.1 \%$, respectively, so their mutual proportions oscillated between 1.24 and 1.80. The linkage structure and some properties of water-insoluble glucans obtained from 18 oral S. salivarius isolates were reported by Eifuku and co-workers [24]. Those authors showed that percentage contents of $\alpha-(1 \rightarrow 3)$ - and $\alpha-(1 \rightarrow 6)$-linked D-glucosyl residues and their proportions were dependent on the individual strain and differed greatly among the tested cultures.

In the present series of experiments, a total of 20 structurally diverse glucans were obtained. A predominance of $(1 \rightarrow 3)$-linked $\alpha$-glucans was observed, but no preparations without $\alpha$ - $(1 \rightarrow 6)$ glucose-containing chains were detected. All polymers (labeled as group A) were water-insoluble, and most of them (17) had a linkage structure in which the total content of $\alpha-(1 \rightarrow 3)$-glucosidic bonds was higher than 50\%. An exception were three glucans $\left(\mathrm{A}_{13}, \mathrm{~A}_{16}\right.$, and $\left.\mathrm{A}_{17}\right)$ which contained more than 50\% glucose linked by $(1 \rightarrow 6)$ glycosidic bonds. In these atypical mutans, the ratio of $\alpha-(1 \rightarrow 3)$ - to $\alpha-(1 \rightarrow 6)-$ bonds ranged from 0.82 to 0.97 , and they were all formed by $S$. sobrinus strain 6070 cultivated in three different media (I, TTY, and THB). Based on the structure of these three unique polymers, it can be 
speculated that their water insolubility depends not only on the number of $\alpha-(1 \rightarrow 3)$-linkages but also on other factors such as van der Waals or proton interactions leading to the formation of large and stable macromolecular aggregates (supramolecular structures) with a lowered solubility. This supposition finds its confirmation in studies carried out by Yui and co-workers [10]. Those authors found, by checking typical helix models, that formation of hydrogen bonds involving side residues was a major cause of structural stabilization, increasing the insolubility of the highly branching cariogenic $\alpha$ - $(1 \rightarrow 3)$-glucan. Also Nisizawa and co-workers [23] obtained from various strains of oral streptococci a few insoluble glucans in which $\alpha-(1 \rightarrow 6)$-glucosidic bonds predominated. Those authors suggested that the solubility of these biopolymers depended not only upon their content of $\alpha-(1 \rightarrow 3)$-linkages but also upon some additional factors such as molecular weight or other structural features.

Table 1. Structure and some properties of mutans synthesized by cariogenic streptococcal strains cultivated in various media ${ }^{\mathrm{a}, \mathrm{b}}$.

\begin{tabular}{|c|c|c|c|c|c|c|c|c|}
\hline \multirow{3}{*}{ Strain } & \multirow{3}{*}{ Medium } & \multirow{3}{*}{ Mutan $^{c}$} & \multicolumn{4}{|c|}{ Content of glucosidic linkages (mol\%) } & \multirow{3}{*}{$\begin{array}{l}- \text { Viscosity } \\
-(\mathbf{m P a} \cdot \mathbf{s})\end{array}$} & \multirow{3}{*}{$\begin{array}{c}\text { Optical rotation } \\
\qquad[\alpha]_{D}^{20}\left(^{\circ}\right)\end{array}$} \\
\hline & & & \multicolumn{2}{|c|}{$\alpha-(1 \rightarrow 3)$ chain } & \multicolumn{2}{|c|}{$\alpha-(1 \rightarrow 6)$ chain } & & \\
\hline & & & $\alpha-(1 \rightarrow 3)$ & $\alpha-(1 \rightarrow 3,6)^{d}$ & $\alpha-(1 \rightarrow 6)$ & $\alpha-(1 \rightarrow 3,6)^{\mathrm{e}}$ & & \\
\hline \multirow{6}{*}{$\begin{array}{c}\text { S. sobrinus } \\
\text { /downei } 21020\end{array}$} & I & $\mathrm{A}_{1}$ & 38.7 & 19.7 & 22.1 & 19.5 & 8.3 & +218 \\
\hline & II & $\mathrm{A}_{2}$ & 44.0 & 11.9 & 26.4 & 17.7 & 15.8 & +208 \\
\hline & BHI & $\mathrm{A}_{3}$ & 44.5 & 17.8 & 22.6 & 15.1 & 9.7 & +214 \\
\hline & TTY & $\mathrm{A}_{4}$ & 48.7 & 14.0 & 24.9 & 12.4 & 17.8 & +216 \\
\hline & THB & $\mathrm{A}_{5}$ & 49.1 & 14.0 & 24.5 & 12.4 & 6.6 & +208 \\
\hline & TSB & $\mathrm{A}_{6}$ & 35.7 & 19.6 & 27.7 & 17.0 & 6.8 & +208 \\
\hline \multirow{6}{*}{ S. sobrinus 20381} & I & $\mathrm{A}_{7}$ & 33.8 & 23.0 & 24.0 & 19.2 & 8.3 & +224 \\
\hline & II & $\mathrm{A}_{8}$ & 34.0 & 17.2 & 34.0 & 14.8 & 5.3 & +206 \\
\hline & $\mathrm{BHI}$ & $\mathrm{A}_{9}$ & 35.1 & 19.1 & 29.0 & 16.8 & 9.3 & +144 \\
\hline & TTY & $\mathrm{A}_{10}$ & 36.2 & 23.7 & 20.8 & 19.3 & 10.2 & +210 \\
\hline & THB & $\mathrm{A}_{11}$ & 37.2 & 16.9 & 30.5 & 15.4 & 7.6 & +216 \\
\hline & TSB & $\mathrm{A}_{12}$ & 33.0 & 22.0 & 24.7 & 20.3 & 8.2 & +214 \\
\hline \multirow{6}{*}{ S. sobrinus 6070} & I & $\mathrm{A}_{13}$ & 23.7 & 25.5 & 27.8 & 23.0 & 4.8 & +198 \\
\hline & II & $\mathrm{A}_{14}$ & 28.7 & 25.7 & 22.7 & 22.9 & 25.4 & +224 \\
\hline & $\mathrm{BHI}$ & $\mathrm{A}_{15}$ & 38.5 & 12.7 & 31.9 & 16.9 & 7.1 & +110 \\
\hline & TTY & $\mathrm{A}_{16}$ & 32.4 & 14.5 & 38.7 & 14.4 & 19.9 & +112 \\
\hline & THB & $\mathrm{A}_{17}$ & 26.7 & 18.4 & 33.9 & 21.0 & 6.3 & +208 \\
\hline & TSB & $-{ }^{f}$ & - & - & - & - & - & - \\
\hline \multirow{6}{*}{ S. mutans 6067} & I & $\mathrm{A}_{18}$ & 37.5 & 14.0 & 34.2 & 14.3 & 13.2 & +194 \\
\hline & II & - & - & - & - & - & - & - \\
\hline & $\mathrm{BHI}$ & $\mathrm{A}_{19}$ & 36.9 & 13.7 & 32.7 & 16.7 & 9.6 & +196 \\
\hline & TTY & - & - & - & - & - & - & - \\
\hline & THB & $\mathrm{A}_{20}$ & 54.1 & 0.0 & 45.9 & 0.0 & 3.1 & +174 \\
\hline & TSB & - & - & - & - & - & - & - \\
\hline
\end{tabular}

${ }^{a}$ Media: I, Quivey and Kriger [25]; II, Fuglsang et al. [26]; BHI, Brain Heart Infusion; TTY, Hamada and Torii [27]; THB, Todd Hewitt Broth; TSB, Tripticase Soy Broth. ${ }^{\mathrm{b}}$ Culture conditions: medium, $400 \mathrm{~mL}$; temperature, $37{ }^{\circ} \mathrm{C}$; cultivation time, $24 \mathrm{~h}$; aerobic conditions. ${ }^{\mathrm{c}}$ Mutan synthesis conditions: culture supernate, $400 \mathrm{~mL}$, pH-value, not regulated; sucrose, $3 \% ; \mathrm{NaN}_{3}, 0.05 \%$; temperature, $37^{\circ} \mathrm{C}$; reaction time, $24 \mathrm{~h}$; static conditions. ${ }^{\mathrm{d}}$ Position 6 is a branching point. ${ }^{\mathrm{e}}$ Position 3 is a branching point. ${ }^{\mathrm{f}}$ Not detected. Note. The mean of triplicate experiments is shown. Standard deviations (not shown) between the values obtained in each experiment for glucosidic linkages content, viscosity, and optical rotation were less than $3 \%$. 
Figure 1. ${ }^{1} \mathrm{H}-\mathrm{NMR}$ spectra of selected streptococcal mutans. Anomeric signals of: (A) $\quad \alpha-(1 \rightarrow 3)-$-linked glucose; (B) $\alpha-(1 \rightarrow 3)$-linked glucose substituted at $O-6$; (C) $\alpha-(1 \rightarrow 6)$-linked glucose substituted at $O-3$; (D) $\alpha-(1 \rightarrow 6)$-linked glucose. Samples were dissolved in $30 \% \mathrm{NaOD}$ in $\mathrm{D}_{2} \mathrm{O}$ and spectra were recorded at $300 \mathrm{MHz}$ at $60{ }^{\circ} \mathrm{C}$.

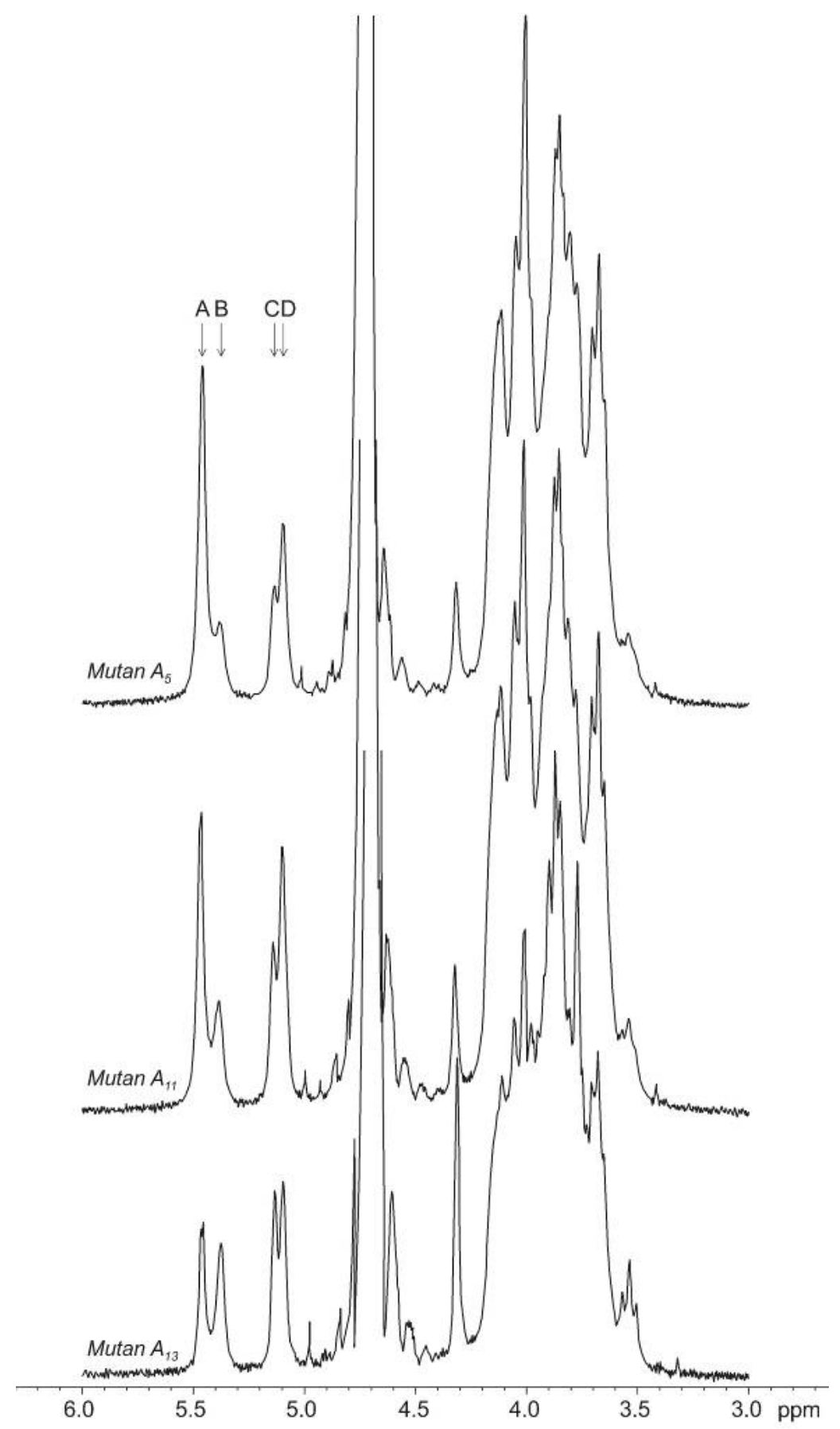

Except for mutan $\mathrm{A}_{20}$, all remaining polymers had a highly branched structure. The highest percentage content of $\alpha-(1 \rightarrow 3)$-linkages (about $63 \%$ ) was found in mutans $A_{3}, A_{4}$, and $A_{5}$, which were synthesized by the strain of $S$. sobrinus/downei 21020 grown in the BHI, TTY, and THB media. The proportion of $(1 \rightarrow 3)$ - to $(1 \rightarrow 6)$ - linkages in the structure of these biopolymers was about 1.7 . Some strains of mutans streptococci (S. sobrinus 6070 and S. mutans 6067) grown in TSB, II, and TTY media did not produce any mutan. The great structural diversity of the investigated mutans also had an 
effect on their physical properties. For example, the values of viscosity and specific optical rotation obtained for those mutans were diversified and oscillated between $3.1 \mathrm{mPa} \cdot \mathrm{s}$ and $25.4 \mathrm{mPa} \cdot \mathrm{s}$ (glucans $\mathrm{A}_{20}$ and $\mathrm{A}_{14}$ ), and between $[\alpha]_{D}^{20}+110^{\circ}$ and $[\alpha]_{D}^{20}+224^{\circ}$ (mutans $\mathrm{A}_{15}$ and $\mathrm{A}_{7}$ ).

As it has been shown in our previous report [7], the strain S. sobrinus/downei 21020 cultivated in medium I produced the largest amount of native mutan, with a yield much higher than any previously reported in the literature. Here, this mutan $\left(A_{1}\right)$ was characterized by a high content of total $\alpha-(1 \rightarrow 3)$ linkages $(58.4 \%)$, and a (1.4 times) larger proportion of $\alpha-(1 \rightarrow 3)$ - compared to $\alpha-(1 \rightarrow 6)$-linkages. Hence, the strain S. sobrinus/downei 21020 and medium I were chosen for further studies in which other culturing parameters affecting the structure of mutan were evaluated.

Table 2 shows the structure and some properties of mutans produced by the selected streptococcal strain grown in medium I under different culture conditions. These conditions were established by changing those operating parameters (initial medium $\mathrm{pH}$, temperature, time of cultivation, glucose concentration in the medium, and type of culture) which have a relatively wide range of action on mutan formation. Depending on the culturing factor used, five groups of glucans (designated as B, C, D, E, and F), comprising 23 polymers, were obtained. Those glucans differed widely in their structure and properties. Although all of them were water-insoluble, and had a highly branched structure containing much more than $50 \%$ of $\alpha-(1 \rightarrow 3)$-linked glucosyl residues, they showed a moderate structural dissimilarity and differed in the number of the analyzed linkages and their mutual proportion. However, no strict correlations between the culturing factors used and the amount or the proportion of particular linkages in the mutan molecule were found. The highest percentage content of $\alpha-(1 \rightarrow 3)$-bonds $(73.4 \%)$ and the highest ratio of $\alpha-(1 \rightarrow 3)$ - to $\alpha-(1 \rightarrow 6)$-linkages (about 2.8$)$ were found in mutan $\mathrm{D}_{6}$ synthesized by streptococci grown in a medium containing $1 \%$ of glucose. The lowest values of these structural variables (54.5\% and 1.2, respectively) were recorded for mutan $\mathrm{E}_{2}$. Walker and co-workers [28,29] studied the effect of a variety of growth conditions on extracellular glucosyltransferase activities of $S$. mutans strains in continuous culture. The authors showed that each variation in the relative activities of the particular Gtfs resulted in such a diversity of glucans synthesized from sucrose that structural analysis of those glucans was virtually meaningless without specifying the conditions of growth of the organism by which they were synthesized.

Table 2. Structure and some properties of mutans produced under different culture conditions by S. sobrinus/downei 21020 grown in medium I.

\begin{tabular}{|c|c|c|c|c|c|c|c|}
\hline \multirow{3}{*}{ Factor varied $^{a, b}$} & \multirow{3}{*}{ Mutan $^{c}$} & \multicolumn{4}{|c|}{ Content of glucosidic linkages (mol\%) } & \multirow{3}{*}{ Viscosity (mPa.s) } & \multirow{3}{*}{$\begin{array}{c}\text { Optical rotation } \\
\qquad[\boldsymbol{\alpha}]_{D}^{20}\left(^{\circ}\right)\end{array}$} \\
\hline & & \multicolumn{2}{|c|}{$\alpha-(1 \rightarrow 3)$ chain } & \multicolumn{2}{|c|}{$\alpha-(1 \rightarrow 6)$ chain } & & \\
\hline & & $\alpha-(1 \rightarrow 3)$ & $\alpha-(1 \rightarrow 3,6)^{d}$ & $\alpha-(1 \rightarrow 6)$ & $\alpha-(1 \rightarrow 3,6)^{\mathrm{e}}$ & & \\
\hline \multicolumn{8}{|c|}{ Initial $\mathrm{pH}$ of the medium } \\
\hline 6.0 & $\mathrm{~B}_{1}$ & 56.6 & 11.7 & 20.0 & 11.7 & 11.7 & +184 \\
\hline 6.5 & $\mathrm{~B}_{2}$ & 43.6 & 15.8 & 26.0 & 14.6 & 18.5 & +242 \\
\hline 7.0 & $\mathrm{~B}_{3}$ & 43.8 & 16.1 & 26.0 & 14.1 & 16.1 & +220 \\
\hline 7.5 & $\mathrm{~B}_{4}$ & 38.5 & 17.8 & 26.8 & 16.9 & 15.5 & +222 \\
\hline 8.0 & $\mathrm{~B}_{5}$ & 41.4 & 17.9 & 24.0 & 16.7 & 13.5 & +220 \\
\hline 8.5 & $\mathrm{~B}_{6}$ & 57.9 & 9.5 & 23.2 & 9.4 & 21.0 & +240 \\
\hline
\end{tabular}


Table 2. Cont.

\begin{tabular}{|c|c|c|c|c|c|c|c|}
\hline \multirow{3}{*}{ Factor varied $^{\mathbf{a}, \mathbf{b}}$} & \multirow{3}{*}{$\operatorname{Mutan}^{\mathrm{c}}$} & \multicolumn{4}{|c|}{ Content of glucosidic linkages (mol\%) } & \multirow{3}{*}{ Viscosity (mPa.s) } & \multirow{3}{*}{$\begin{array}{c}\text { Optical rotation } \\
\qquad[\boldsymbol{\alpha}]_{D}^{20}\left(^{\circ}\right)\end{array}$} \\
\hline & & \multicolumn{2}{|c|}{$\alpha-(1 \rightarrow 3)$ chain } & \multicolumn{2}{|c|}{$\alpha-(1 \rightarrow 6)$ chain } & & \\
\hline & & $\alpha-(1 \rightarrow 3)$ & $\alpha-(1 \rightarrow 3,6)^{\mathrm{d}}$ & $\alpha-(1 \rightarrow 6)$ & $\alpha-(1 \rightarrow 3,6)^{\mathrm{e}}$ & & \\
\hline \multicolumn{8}{|c|}{ Culture temperature $\left({ }^{\circ} \mathrm{C}\right)$} \\
\hline 30 & $\mathrm{C}_{1}$ & 62.9 & 3.9 & 27.8 & 5.4 & 5.0 & +198 \\
\hline 37 & $\mathrm{C}_{2}$ & 48.0 & 12.9 & 27.1 & 12.0 & 17.0 & +196 \\
\hline 40 & $\mathrm{C}_{3}$ & 56.0 & 8.9 & 24.4 & 10.7 & 19.3 & +210 \\
\hline \multicolumn{8}{|c|}{ Glucose concentration (\%) } \\
\hline 0.00 & $D_{1}$ & 43.0 & 15.8 & 25.6 & 15.6 & 5.4 & +148 \\
\hline 0.05 & $\mathrm{D}_{2}$ & 49.6 & 17.9 & 17.1 & 15.4 & 8.1 & +210 \\
\hline 0.10 & $\mathrm{D}_{3}$ & 42.7 & 17.3 & 23.5 & 16.5 & 10.5 & +148 \\
\hline 0.25 & $\mathrm{D}_{4}$ & 48.9 & 14.8 & 24.7 & 11.6 & 3.8 & +152 \\
\hline 0.50 & $\mathrm{D}_{5}$ & 57.5 & 14.9 & 15.6 & 12.0 & 5.9 & +146 \\
\hline 1.00 & $\mathrm{D}_{6}$ & 59.8 & 13.6 & 14.4 & 12.4 & 5.7 & +218 \\
\hline \multicolumn{8}{|l|}{ Cultivation time (h) } \\
\hline 6 & $\mathrm{E}_{1}$ & 57.6 & 7.2 & 27.3 & 7.9 & 22.9 & +260 \\
\hline 12 & $\mathrm{E}_{2}$ & 41.3 & 13.2 & 33.4 & 12.1 & 11.2 & +230 \\
\hline 18 & $\mathrm{E}_{3}$ & 33.7 & 22.2 & 23.3 & 20.8 & 6.9 & +218 \\
\hline 24 & $\mathrm{E}_{4}$ & 34.1 & 24.4 & 18.2 & 23.3 & 3.9 & +206 \\
\hline 36 & $\mathrm{E}_{5}$ & 43.2 & 21.1 & 16.8 & 18.9 & 2.4 & +208 \\
\hline 48 & $\mathrm{E}_{6}$ & 42.4 & 21.5 & 16.0 & 20.1 & 2.3 & +202 \\
\hline \multicolumn{8}{|l|}{ Kind of culture: } \\
\hline Anaerobic $^{f}$ & $\mathrm{~F}_{1}$ & 43.5 & 16.1 & 25.7 & 14.6 & 7.7 & +222 \\
\hline aerobic & $\mathrm{F}_{2}$ & 34.8 & 24.3 & 19.4 & 21.5 & 4.5 & +210 \\
\hline
\end{tabular}

${ }^{a}$ Except for the factor that varied as indicated, all other culture and environmental conditions affecting respective stages of efficient mutan production had been standardized earlier [7] and applied here as optimal. ${ }^{\mathrm{b}}$ Optimal culture conditions: medium $\mathrm{pH}, 7.5$; temperature, $37{ }^{\circ} \mathrm{C}$; glucose concentration, $0.1 \%$; cultivation time, $30 \mathrm{~h}$; aerobic conditions. ${ }^{\mathrm{c}}$ Optimal conditions for mutan synthesis: culture supernate $\mathrm{pH}, 6.0$; sucrose, $15 \%$; $\mathrm{NaN}_{3}, 0.05 \%$; temperature, $37{ }^{\circ} \mathrm{C}$; reaction time, $36 \mathrm{~h}$; static conditions. ${ }^{\mathrm{d} \text {,e }}$ See Table $1 .{ }^{\mathrm{f}}$ The culture was run in a microbial anaerostat. Note. See Table 1.

In the present study, the streptococcal mutans obtained under different culture conditions were also tested for their viscosity and optical rotation. The values of these parameters ranged from $2.3 \mathrm{mPa} \cdot \mathrm{s}$ to $22.9 \mathrm{mPa} \cdot \mathrm{s}$ (glucans $\mathrm{E}_{6}$ and $\mathrm{E}_{1}$ ) and from $[\alpha]_{D}^{20}+148^{\circ}$ to $[\alpha]_{D}^{20}+260^{\circ}$ (polymers $\mathrm{D}_{1}$ and $\mathrm{E}_{1}$ ), respectively.

\subsection{Structure and Some Properties of Mutans Synthesized in Post-Culture Supernates Incubated under Different Environmental Conditions}

The mixture of glucosyltransferases present in the supernatant fluid obtained after cultivation of the cariogenic strain S. sobrinus/downei 21020 was subjected to different environmental conditions influencing the formation of streptococcal mutan (Table 3). Depending on basic glucan production variables, i.e., $\mathrm{pH}$, temperature, reaction time, sucrose source, and its concentration, five groups of mutans (designated as G, H, I, J, and K), comprising 33 structurally diversified polymers, were obtained. 
Table 3. Structure and some properties of mutans formed by streptococcal glucosyltransferases in post-culture supernates incubated under different environmental conditions.

\begin{tabular}{|c|c|c|c|c|c|c|c|}
\hline \multirow{3}{*}{ Factor varied ${ }^{a}$} & \multirow{3}{*}{ Mutan ${ }^{b}$} & \multicolumn{4}{|c|}{ Content of glucosidic linkages (mol\%) } & \multirow{3}{*}{$\begin{array}{c}\text { Viscosity } \\
\text { (mPa.s) }\end{array}$} & \multirow{3}{*}{$\begin{array}{l}\text { Optical } \\
\text { rotation } \\
{[\alpha]_{D}^{20}\left({ }^{\circ}\right)}\end{array}$} \\
\hline & & \multicolumn{2}{|c|}{$\alpha-(1 \rightarrow 3)$ chain } & \multicolumn{2}{|c|}{$\alpha-(1 \rightarrow 6)$ chain } & & \\
\hline & & $\alpha-(1 \rightarrow 3)$ & $\alpha-(1 \rightarrow 3,6)^{\mathrm{c}}$ & $\alpha-(1 \rightarrow 6)$ & $\alpha-(1 \rightarrow 3,6)^{\mathrm{d}}$ & & \\
\hline \multicolumn{8}{|c|}{$\mathrm{pH}$ of culture supernate } \\
\hline 5.0 & $\mathrm{G}_{1}$ & 26.4 & 24.2 & 26.4 & 23.0 & 4.9 & +208 \\
\hline 5.5 & $\mathrm{G}_{2}$ & 28.2 & 22.4 & 26.5 & 22.9 & 5.3 & +210 \\
\hline 6.0 & $\mathrm{G}_{3}$ & 31.1 & 23.9 & 22.1 & 22.9 & 5.6 & +210 \\
\hline 6.5 & $\mathrm{G}_{4}$ & 33.6 & 23.5 & 19.2 & 23.7 & 6.0 & +216 \\
\hline 7.0 & $\mathrm{G}_{5}$ & 39.2 & 21.1 & 18.6 & 21.1 & 23.9 & +226 \\
\hline 7.5 & $\mathrm{G}_{6}$ & 45.0 & 19.5 & 15.3 & 20.2 & 19.6 & +220 \\
\hline 8.0 & $\mathrm{G}_{7}$ & 60.3 & 15.0 & 11.8 & 12.9 & 30.2 & +232 \\
\hline \multicolumn{8}{|c|}{ Reaction temperature $\left({ }^{\circ} \mathrm{C}\right)$} \\
\hline 20 & $\mathrm{H}_{1}$ & 17.3 & 25.7 & 32.0 & 25.0 & 7.1 & +184 \\
\hline 30 & $\mathrm{H}_{2}$ & 27.7 & 23.9 & 26.2 & 22.2 & 6.6 & +206 \\
\hline 37 & $\mathrm{H}_{3}$ & 32.5 & 22.7 & 23.8 & 21.0 & 5.7 & +218 \\
\hline 40 & $\mathrm{H}_{4}$ & 35.5 & 21.9 & 22.4 & 20.2 & 6.0 & +214 \\
\hline 45 & $\mathrm{H}_{5}$ & 52.9 & 14.8 & 18.7 & 13.6 & 15.2 & +234 \\
\hline 50 & $\mathrm{H}_{6}$ & 51.0 & 12.9 & 23.9 & 12.2 & 15.5 & +240 \\
\hline \multicolumn{8}{|c|}{ Sucrose concentration (\%) ${ }^{\mathrm{e}}$} \\
\hline 1 & $\mathrm{I}_{1}$ & 45.4 & 20.7 & 16.3 & 17.6 & 4.9 & +212 \\
\hline 2 & $\mathrm{I}_{2}$ & 43.4 & 21.9 & 16.6 & 18.1 & 4.4 & +212 \\
\hline 3 & $\mathrm{I}_{3}$ & 40.8 & 22.2 & 18.0 & 19.0 & 4.9 & +208 \\
\hline 5 & $\mathrm{I}_{4}$ & 36.9 & 22.6 & 20.4 & 20.1 & 5.1 & +198 \\
\hline 10 & $\mathrm{I}_{5}$ & 31.2 & 23.4 & 23.6 & 21.8 & 4.9 & +192 \\
\hline 15 & $\mathrm{I}_{6}$ & 30.0 & 23.2 & 25.3 & 21.5 & 5.8 & +194 \\
\hline 20 & $\mathrm{I}_{7}$ & 30.3 & 23.1 & 26.1 & 20.5 & 5.3 & +202 \\
\hline \multicolumn{8}{|l|}{ Reaction time (h) } \\
\hline 6 & $\mathrm{~J}_{1}$ & 31.0 & 21.6 & 26.9 & 20.5 & 11.8 & +216 \\
\hline 12 & $\mathrm{~J}_{2}$ & 33.2 & 20.7 & 26.6 & 19.5 & 11.1 & +220 \\
\hline 18 & $\mathrm{~J}_{3}$ & 34.2 & 20.8 & 25.6 & 19.4 & 9.4 & +218 \\
\hline 24 & $\mathrm{~J}_{4}$ & 33.8 & 20.5 & 26.1 & 19.6 & 9.1 & +218 \\
\hline 36 & $\mathrm{~J}_{5}$ & 37.2 & 19.7 & 24.8 & 18.3 & 7.5 & +218 \\
\hline 48 & $\mathrm{~J}_{6}$ & 38.3 & 19.4 & 24.4 & 17.9 & 6.8 & +214 \\
\hline \multicolumn{8}{|l|}{ Sucrose source ${ }^{f}$} \\
\hline I & $\mathrm{K}_{1}$ & 30.1 & 22.9 & 21.5 & 25.5 & 5.7 & +210 \\
\hline II & $\mathrm{K}_{2}$ & 30.0 & 22.9 & 24.9 & 22.2 & 5.1 & +200 \\
\hline III & $\mathrm{K}_{3}$ & 30.1 & 22.7 & 25.0 & 22.2 & 5.3 & +212 \\
\hline IV & $\mathrm{K}_{4}$ & 27.4 & 24.2 & 25.4 & 23.0 & 5.9 & +212 \\
\hline $\mathrm{V}$ & $\mathrm{K}_{5}$ & 31.7 & 22.2 & 23.9 & 22.2 & 5.8 & +192 \\
\hline VI & $\mathrm{K}_{6}$ & 32.6 & 21.7 & 22.2 & 23.5 & 5.9 & +212 \\
\hline VII & $\mathrm{K}_{7}$ & 30.6 & 22.2 & 24.5 & 22.7 & 5.7 & $\begin{array}{r}+210 \\
\end{array}$ \\
\hline
\end{tabular}

\footnotetext{
${ }^{a}$ Except for the factor that varied as indicated, all other environmental conditions for efficient mutan production in post-culture liquids had been standardized earlier [7] and applied here as optimal. ${ }^{\mathrm{b}}$ Optimal conditions for mutan synthesis: culture supernate $\mathrm{pH}, 6.0$; sucrose, $15 \%$; $\mathrm{NaN}_{3}, 0.05 \%$; temperature, $37{ }^{\circ} \mathrm{C}$; reaction time, $36 \mathrm{~h}$; static conditions. ${ }^{\mathrm{c}, \mathrm{d}}$ See Table $1\left({ }^{\mathrm{d}, \mathrm{e}}\right) .{ }^{\mathrm{e}}$ Analytical grade reagent. ${ }^{\mathrm{f}}$ Beet sugar; granulated sugar as a substitute for pure sucrose coming from the following Polish sugar factories: Strzyżów (I), Wróblin (II), Świdnica (III), Glinojeck (IV), Krasnystaw (V), Cerekiew (VI), and Małoszyn (VII). Note. See Table 1.
} 
All mutans were water-insoluble and had a highly branched structure. Almost all of them (32) had a linkage structure with a predominance of $\alpha-(1 \rightarrow 3)$-glucosidic bonds (i.e., their content was higher than $50 \%$ ). An exception was the water-insoluble glucan $\mathrm{H}_{1}$, synthesized at $20{ }^{\circ} \mathrm{C}$, which contained more than $50 \%$ of $\alpha-(1 \rightarrow 6)$-links. In this structurally unique mutan, the ratio of $\alpha-(1 \rightarrow 3)-$ to $\alpha-(1 \rightarrow 6)$-linkages was 0.75 .

The examined biopolymers showed a moderate structural dissimilarity and differed in the number of the analyzed linkages and their mutual proportion. Though not statistically significant, some correlations between the changing conditions of mutan synthesis and the amount or the proportion of particular linkages in the polymer molecule were observed. The total percentage content of $\alpha-(1 \rightarrow 3)$ glycosidic bonds and the ratio of the total amount of $\alpha-(1 \rightarrow 3)$ - to $\alpha-(1 \rightarrow 6)$-linkages increased gradually along with an increase in supernate $\mathrm{pH}$, reaction time, and temperature. By contrast, an increase in the concentration of sucrose in the reaction mixture lowered the total content and mutual proportion of the two linkages in the mutan molecule. On the other hand, replacement of pure sucrose with the much cheaper granulated sugar beet coming from various sugar factories had no major effect on the linkage structure of the mutan formed. The highest percentage content of $\alpha-(1 \rightarrow 3)$-links $(75.3)$ and the highest ratio of $\alpha-(1 \rightarrow 3)$ - to $\alpha-(1 \rightarrow 6)$-linkages (about 3.05) was recorded for mutan $G_{7}$ obtained in a reaction mixture adjusted to $\mathrm{pH}$ 8.0. Among the biopolymers obtained in this series of experiments, mutan $\mathrm{G}_{7}$ also showed the highest viscosity $(30.2 \mathrm{mPa} \cdot \mathrm{s})$ and had a relatively high positive optical rotation $\left(+232^{\circ}\right)$.

The diverse environmental conditions used for enzymatic formation of mutan influenced not only the structure but also the physical properties of the biopolymer. For example, the values of viscosity and specific optical rotation obtained for the analyzed mutans were diversified and ranged from $4.4 \mathrm{mPa} \cdot \mathrm{s}$ to $30.2 \mathrm{mPa} \cdot \mathrm{s}$ (glucans $\mathrm{I}_{2}$ and $\mathrm{G}_{7}$ ) and from $[\alpha]_{D}^{20}+184^{\circ}$ to $[\alpha]_{D}^{20}+240^{\circ}$ (mutans $\mathrm{H}_{1}$ and $\mathrm{H}_{6}$ ), respectively. Data concerning the intrinsic viscosity and the optical rotation of mutans are rarely given in the literature. The values of these parameters provided by some authors [19,30,31] for water-insoluble biopolymers synthesized under optimal conditions by various strains of oral streptococci are relatively high and fluctuate within the limits of $0.46-9.6[\eta]_{20} \mathrm{dL} / \mathrm{g}$ and from $[\alpha]_{D}^{20}+197^{\circ}$ to $[\alpha]_{D}^{20}+228^{\circ}$, respectively. As showed by Tsumuraya and Misaki [31], the high positive values of optical rotation obtained for streptococcal mutans are indicative of $\alpha$-D-glucosidic linkages. Also, Rees and Scott [32] have provided evidence that $\alpha-(1 \rightarrow 3)$ linkages in the main chain of glucan confer rigidity and hence high viscosity.

\subsection{Effect of Structurally Diverse Mutans on Mutanase Synthesis Produced by T. harzianum}

Mutan is known as one of the most effective inducers of mutanase synthesis [6,7]. In the chemical structure of this polymeric homoglucan, only $\alpha-(1 \rightarrow 3)$-linkages can be responsible for specific induction of mutanase. Hence, it seems that the polymers with greater numbers of $\alpha-(1 \rightarrow 3)$-links should be much more effective mutanase inducers than the ones with a low content of these bonds. In this context, it is also interesting to know whether there is a close relationship between the content of $\alpha-(1 \rightarrow 3)$-linkages and the activity of fungal mutanase. To answer those questions, 76 structurally diverse mutans, obtained in previous experiments, were used as sole carbon and energy sources for the induction of mutanase production by $T$. harzianum in shaken flask cultures. The content of 
$\alpha$ - $(1 \rightarrow 3)$-linkages in the particular glucans ranged from $43 \%\left(\right.$ mutan $\left.\mathrm{H}_{1}\right)$ to over $75 \%\left(\right.$ mutan $\left.\mathrm{G}_{7}\right)$. The inductive effect of mutans on mutanase synthesis was measured as enzymatic activity of supernate obtained after 3 days of fungus cultivation.

As it can be seen from the data summarized in Table 4, the best inducers of mutanase production were mutans $A_{13}, H_{1}$, and $K_{5}$, for which the enzyme reached after 3 days of cultivation the activity of $1.051,0.792$, and $0.761 \mathrm{U} / \mathrm{mL}$, respectively. High mutanolytic activities $(0.600-0.707 \mathrm{U} / \mathrm{mL})$ were also at the same time found for 18 other glucans. For comparison, the lowest level of enzyme induction (0.144-0.188 U/mL) was recorded for mutans $\mathrm{I}_{2}, \mathrm{I}_{4}, \mathrm{I}_{5}, \mathrm{E}_{5}$, and $\mathrm{E}_{6}$. The data obtained from statistical analysis (Pearson correlation coefficient $\mathrm{R}=-0.159$, determination coefficient $\mathrm{R}^{2}=0.0252$, linear regression $\mathrm{y}=-0.0044 \mathrm{x}+0.7681, p<0.05)$ indicate a lack of correlation between the total percentage content of $\alpha-(1 \rightarrow 3)$-linkages in the mutan molecule and the mutanase activity induced by it (Figure 2 ). Thus, despite biosynthetic differences causing structural variation in the mutans, it did not matter which mutan structures were used to induce mutanase production. Based on these results, it can be supposed that the level of mutanase production (expressed as its activity) depends not only on the number of $\alpha-(1 \rightarrow 3)$-linkages in the mutan molecule but also on other factors such as the spatial arrangement of the linkages in the inducer molecule and the accessibility of the enzyme to $\alpha-(1 \rightarrow 3)$ sequences. This supposition is confirmed by the fact that in some cases (Table 4) the highest activities of mutanase were achieved for polymers with a low content of $\alpha-(1 \rightarrow 3)$-linkages (e.g., glucans $\mathrm{A}_{13}$ and $\left.\mathrm{H}_{1}\right)$. In other cases, a relatively high content of $\alpha-(1 \rightarrow 3)$-bonds in a mutan induced a low mutanolytic activity (e.g., polymers $\mathrm{I}_{2}, \mathrm{E}_{5}$, and $\mathrm{E}_{6}$ ).

Table 4. Influence of structurally diversified mutans on mutanase production by T. harzianum F-340 in shaken flask cultures.

\begin{tabular}{|c|c|c|c|c|c|c|c|c|}
\hline \multicolumn{2}{|r|}{ Mutan } & \multirow{2}{*}{$\begin{array}{c}\text { Mutanase } \\
\text { activity } \\
\text { (U/mL) }\end{array}$} & \multirow{2}{*}{\multicolumn{2}{|c|}{$\begin{array}{cc} & \text { Mutan } \\
& \text { Total content of } \\
\mathrm{N}^{\circ} & \alpha-(1 \rightarrow 3)-\text { linkages } \\
& (\mathrm{mol} \%) \\
\end{array}$}} & \multirow{2}{*}{$\begin{array}{c}\text { Mutanase } \\
\text { activity } \\
(\mathrm{U} / \mathrm{mL}) \\
\end{array}$} & \multicolumn{2}{|r|}{ Mutan } & \multirow{2}{*}{$\begin{array}{c}\text { Mutanase } \\
\text { activity } \\
\text { (U/mL) }\end{array}$} \\
\hline $\mathrm{N}^{\circ}$ & $\begin{array}{c}\begin{array}{c}\text { Total content of } \\
\alpha-(1 \rightarrow 3)-\text { linkages } \\
(\mathrm{mol} \%)\end{array} \\
\end{array}$ & & & & & $\mathrm{N}^{\circ}$ & $\begin{array}{c}\text { Total content of } \\
\alpha-(1 \rightarrow 3)-\text { linkages } \\
(\mathrm{mol} \%) \\
\end{array}$ & \\
\hline $\mathrm{A}_{1}$ & 58.4 & 0.406 & $\mathrm{C}_{1}$ & 66.8 & 0.665 & $\mathrm{H}_{3}$ & 55.2 & 0.564 \\
\hline $\mathrm{A}_{2}$ & 55.9 & 0.445 & $\mathrm{C}_{2}$ & 60.9 & 0.648 & $\mathrm{H}_{4}$ & 57.4 & 0.632 \\
\hline $\mathrm{A}_{3}$ & 62.3 & 0.545 & $\mathrm{C}_{3}$ & 64.9 & 0.600 & $\mathrm{H}_{5}$ & 67.7 & 0.514 \\
\hline $\mathrm{A}_{4}$ & 62.7 & 0.507 & $\mathrm{D}_{1}$ & 58.8 & 0.591 & $\mathrm{H}_{6}$ & 63.9 & 0.566 \\
\hline $\mathrm{A}_{5}$ & 63.1 & 0.441 & $\mathrm{D}_{2}$ & 67.5 & 0.570 & $\mathrm{I}_{1}$ & 66.1 & 0.253 \\
\hline $\mathrm{A}_{6}$ & 55.3 & 0.458 & $\mathrm{D}_{3}$ & 60.0 & 0.665 & $\mathrm{I}_{2}$ & 65.3 & 0.144 \\
\hline $\mathrm{A}_{7}$ & 56.8 & 0.579 & $\mathrm{D}_{4}$ & 63.7 & 0.542 & $\mathrm{I}_{3}$ & 63.0 & 0.201 \\
\hline $\mathrm{A}_{8}$ & 51.2 & 0.293 & $\mathrm{D}_{5}$ & 72.4 & 0.536 & $\mathrm{I}_{4}$ & 59.5 & 0.168 \\
\hline $\mathrm{A}_{9}$ & 54.2 & 0.665 & $\mathrm{D}_{6}$ & 73.4 & 0.547 & $\mathrm{I}_{5}$ & 54.6 & 0.175 \\
\hline $\mathrm{A}_{10}$ & 59.9 & 0.446 & $\mathrm{E}_{1}$ & 64.8 & 0.454 & $\mathrm{I}_{6}$ & 53.2 & 0.256 \\
\hline $\mathrm{A}_{11}$ & 54.1 & 0.542 & $\mathrm{E}_{2}$ & 54.5 & 0.519 & $\mathrm{I}_{7}$ & 53.4 & 0.300 \\
\hline$A_{12}$ & 55.0 & 0.535 & $\mathrm{E}_{3}$ & 55.9 & 0.633 & $\mathrm{~J}_{1}$ & 52.6 & 0.509 \\
\hline$A_{13}$ & 49.2 & 1.051 & $\mathrm{E}_{4}$ & 58.5 & 0.707 & $\mathrm{~J}_{2}$ & 53.9 & 0.656 \\
\hline $\mathrm{A}_{14}$ & 54.4 & 0.291 & $\mathrm{E}_{5}$ & 64.3 & 0.170 & $\mathrm{~J}_{3}$ & 55.0 & 0.582 \\
\hline $\mathrm{A}_{15}$ & 51.2 & 0.389 & $\mathrm{E}_{6}$ & 63.9 & 0.188 & $\mathrm{~J}_{4}$ & 54.3 & 0.572 \\
\hline $\mathrm{A}_{16}$ & 46.9 & 0.402 & $\mathrm{~F}_{1}$ & 59.6 & 0.558 & $\mathrm{~J}_{5}$ & 56.9 & 0.635 \\
\hline$A_{17}$ & 45.1 & 0.396 & $\mathrm{~F}_{2}$ & 59.1 & 0.527 & $\mathrm{~J}_{6}$ & 57.7 & 0.686 \\
\hline
\end{tabular}


Table 4. Cont.

\begin{tabular}{|c|c|c|c|c|c|c|c|c|}
\hline \multicolumn{2}{|r|}{ Mutan } & \multirow{2}{*}{$\begin{array}{l}\text { Mutanase } \\
\text { activity }\end{array}$} & \multicolumn{2}{|r|}{\begin{tabular}{|c|} 
Mutan \\
Total content of
\end{tabular}} & \multirow{2}{*}{$\begin{array}{l}\text { Mutanase } \\
\text { activity }\end{array}$} & \multicolumn{2}{|r|}{ Mutan } & \multirow{2}{*}{$\begin{array}{c}\text { Mutanase } \\
\text { activity }\end{array}$} \\
\hline $\mathrm{N}^{\circ}$ & $\begin{array}{c}\text { Total content of } \\
\begin{array}{c}\alpha-(1 \rightarrow 3)-\text { linkages } \\
(\mathrm{mol} \%)\end{array}\end{array}$ & & $\mathrm{N}^{\circ}$ & $\begin{array}{c}\text { Total content of } \\
\begin{array}{c}\alpha-(1 \rightarrow 3)-\text { linkages } \\
(\mathrm{mol} \%)\end{array}\end{array}$ & & $\mathrm{N}^{\circ}$ & $\begin{array}{c}\text { Total content of } \\
\begin{array}{c}\alpha-(1 \rightarrow 3)-\text { linkages } \\
(\mathrm{mol} \%)\end{array}\end{array}$ & \\
\hline $\mathrm{A}_{18}$ & 51.5 & 0.514 & $\mathrm{G}_{1}$ & 50.6 & 0.347 & $\mathrm{~K}_{1}$ & 53.0 & 0.573 \\
\hline $\mathrm{A}_{19}$ & 50.6 & 0.452 & $\mathrm{G}_{2}$ & 50.6 & 0.230 & $\mathrm{~K}_{2}$ & 52.9 & 0.566 \\
\hline $\mathrm{A}_{20}$ & 54.1 & 0.542 & $\mathrm{G}_{3}$ & 55.0 & 0.302 & $\mathrm{~K}_{3}$ & 52.8 & 0.600 \\
\hline $\mathrm{B}_{1}$ & 68.3 & 0.585 & $\mathrm{G}_{4}$ & 57.1 & 0.560 & $\mathrm{~K}_{4}$ & 51.6 & 0.691 \\
\hline $\mathrm{B}_{2}$ & 59.4 & 0.614 & $\mathrm{G}_{5}$ & 60.3 & 0.562 & $\mathrm{~K}_{5}$ & 53.9 & 0.761 \\
\hline $\mathrm{B}_{3}$ & 59.9 & 0.572 & $\mathrm{G}_{6}$ & 64.5 & 0.634 & $\mathrm{~K}_{6}$ & 54.3 & 0.631 \\
\hline $\mathrm{B}_{4}$ & 56.3 & 0.543 & $\mathrm{G}_{7}$ & 75.3 & 0.667 & $\mathrm{~K}_{7}$ & 52.8 & 0.618 \\
\hline $\mathrm{B}_{5}$ & 59.3 & 0.703 & $\mathrm{H}_{1}$ & 43.0 & 0.792 & & & \\
\hline $\mathrm{B}_{6}$ & 67.4 & 0.576 & $\mathrm{H}_{2}$ & 51.6 & 0.573 & & & \\
\hline
\end{tabular}

a Enzyme activity in culture supernatants was measured after 3 days of submerged cultivation of T. harzianum on Mandels optimized medium A containing individual mutans as mutanase inducers $(0.3 \%)$. Note. The mean of triplicate experiments is shown. Standard deviations (not shown) between the values obtained in each experiment for mutanase activity were less than $5 \%$.

Figure 2. Relationship between mutanase activity obtained on particular mutans as enzyme inducers (76 samples) and the total content of $\alpha-(1 \rightarrow 3)$-linkages in each of these polymers (for details see Table 4). The data obtained from statistical analysis: Pearson correlation $(\mathrm{R})$, determination $\left(\mathrm{R}^{2}\right)$, and linear regression $(\mathrm{y}), p<0.05$.

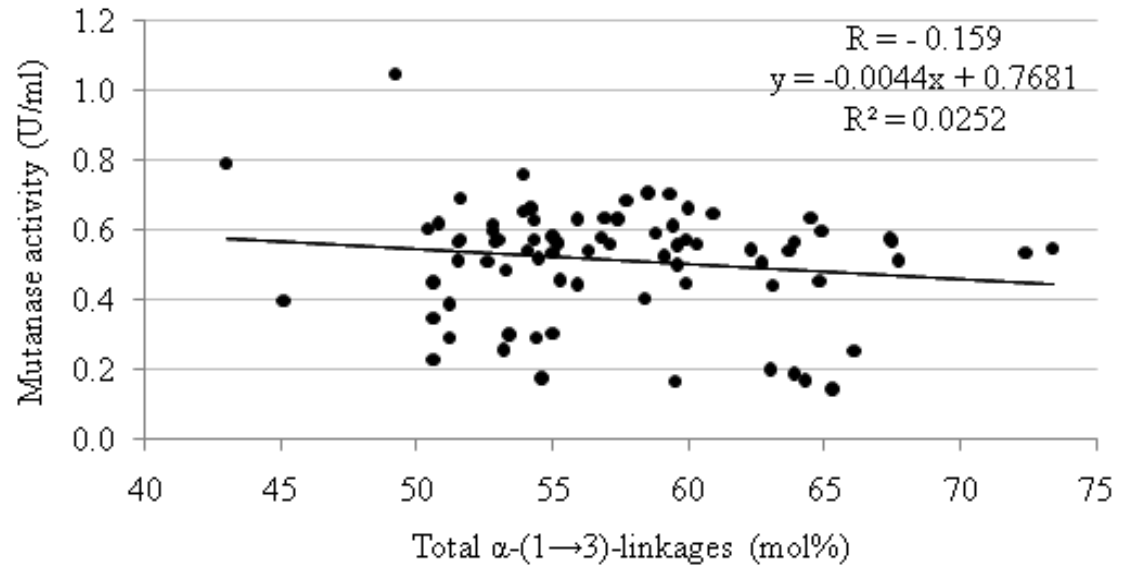

It should be noted (data not shown) that mutans with a higher content of $\alpha-(1 \rightarrow 3)$-linkages (64-76 mol\%) were more susceptible to enzymatic attack of mutanase than the ones containing smaller amounts of these bonds (43-49 mol\%). Similar results were reported in a paper published by Eifuku and co-workers [24], where water-insoluble glucans rich in $\alpha-(1 \rightarrow 3)$-linkages showed a higher susceptibility to hydrolysis by mutanase than by dextranase. 


\section{Experimental}

\subsection{Microorganisms}

The cariogenic streptococci used in this study included Streptococcus mutans 6067, S. sobrinus 6070 (The Collection of Animal Pathogenic Microorganisms, Brno, Czech Republic), S. sobrinus 20381 (formerly S. mutans 20381) (The German Collection of Microorganisms, Braunschweig, Germany) and S. sobrinus/downei CCUG 21020 (formerly S. mutans OMZ 176) (The Culture Collection, University of Göteborg, Göteborg, Sweden). Trichoderma harzianum strain CCM F-340 (Czech Collection of Microorganisms, Brno, Czech Republic) was used as a starting culture for mutanase induction by various preparations of streptococcal mutan.

\subsection{Bacterial Growth Conditions}

Stock cultures of streptococcal strains were stored at $-20{ }^{\circ} \mathrm{C}$ in $50 \%$ glycerol. Unless otherwise stated, the bacteria were grown aerobically in glucose-containing complex media such as Todd-Hewitt broth (THB), tripticase soy broth (TSB), brain-heart infusion (BHI) (Baltimore Biological Laboratory, Cockeysville, MD, USA), and I, II and TTY as given by Quivey and Kriger [25], Fuglsang and co-workers [26], and Hamada and Torii [27], respectively. The media contained in 500-mL flasks, $400 \mathrm{~mL}$ each, were autoclaved for $30 \mathrm{~min}$ at $121^{\circ} \mathrm{C}$. A precultured broth $(24-\mathrm{h}$-old, $0.5 \mathrm{v} / \mathrm{v} \%$ ) of bacteria grown at $37{ }^{\circ} \mathrm{C}$ in the same media was used for flask inoculation. Batch cultures were run at $37^{\circ} \mathrm{C}$ for $24 \mathrm{~h}$ under stationary conditions. Bacteria were grown under strictly anaerobic conditions in a microbial anaerostat (anaeroJar AG 025A, Oxoid, Basingstoke, UK). Some culturing parameters, listed in Table 2, were evaluated as potential factors modifying the structure of mutans. This Table also gives other experimental details.

\subsection{Production of Mutan}

Insoluble mutans were synthesized from sucrose by a mixture of extracellular glucosyltransferases present in the post-culture fluids of cariogenic streptococci. The bacterial biomass was separated by centrifugation at $12,000 \times \mathrm{g}$ for $20 \mathrm{~min}$. Unless otherwise stated, clear supernatant fluid (without $\mathrm{pH}$ adjustment) was allowed to react with sucrose $(3 \%)$ in the presence of $0.05 \%$ sodium azide as a preservative. The water-insoluble glucan formed after incubation at $37^{\circ} \mathrm{C}$ for $24 \mathrm{~h}$ (henceforth referred to as mutan) was collected by centrifugation at $12,000 \times \mathrm{g}$ for $20 \mathrm{~min}$, washed thoroughly with deionized water, and freeze-dried. Some of the important factors influencing the structural diversity of the mutan synthesized in the post-culture supernate as well as other methodological details are specified in Table 3.

\subsection{Trichoderma harzianum Cultivation}

Stock cultures of $T$. harzianum, maintained at $4{ }^{\circ} \mathrm{C}$ on potato dextrose agar slants, were used for inoculations. Liquid medium A (pH 5.3), as described by Mandels and co-workers [33], supplemented with $0.3 \%$ mutan as a mutanase inducer, $0.05 \%$ peptone proteose, and $0.1 \%$ Tween 80 , was used for mutanase production. Shaken cultures were conducted in $500 \mathrm{~mL}$ conical flasks containing $100 \mathrm{~mL}$ of 
sterile medium. The flasks were seeded with conidia to a final concentration of about $2 \times 10^{7} \mathrm{conidia} / \mathrm{mL}$ and placed on an orbital rotary shaker at $300 \mathrm{rpm}$ and $30{ }^{\circ} \mathrm{C}$ for 3 days.

\subsection{Structural Studies}

The structural characteristics of mutans were investigated by ${ }^{1} \mathrm{H}-\mathrm{NMR}$. Mutans $(20 \mathrm{mg})$ were dissolved in $0.6 \mathrm{~mL}$ of $30 \% \mathrm{NaOD}$ in $\mathrm{D}_{2} \mathrm{O}$. The spectra of the alkali-soluble glucans were recorded with an Avance (300 MHz) spectrometer (Bruker BioSpin GmbH, Rheinstetten/Karlsruhe, Germany) at $60{ }^{\circ} \mathrm{C} .{ }^{1} \mathrm{H}$ chemical shifts were estimated using acetone $\left(\delta_{\mathrm{H}} 2.225 \mathrm{ppm}\right)$ as the internal standard. The approximate amounts of $\alpha-(1 \rightarrow 3)$ - and $\alpha-(1 \rightarrow 6)$-glucosidic linkages and those of branched glucose were calculated from an integration of the anomeric proton signal areas [34]. Specific rotation $[\alpha]_{D}^{20}+(c 1 \mathrm{M}$ sodium hydroxide) was measured at $589 \mathrm{~nm}$ in a Perkin Elmer Automatic Polarimeter (Model 341 LC). The intrinsic viscosity of the polysaccharides ( $c 1 \mathrm{M}$ sodium hydroxide) was measured with a Brookfield (Model DV 3) viscometer at $20^{\circ} \mathrm{C}$.

\subsection{Mutanase Assay}

The standard mutanase assay mixture contained $0.5 \mathrm{~mL}$ of $0.2 \%(\mathrm{w} / \mathrm{v})$ dextranase-treated mutan (DTM) in $0.2 \mathrm{M}$ sodium acetate buffer ( $\mathrm{pH} 5.5)$ and $0.5 \mathrm{~mL}$ of a suitably diluted enzyme solution. After $1 \mathrm{~h}$ incubation at $45^{\circ} \mathrm{C}$, the reducing sugars released were quantified by the Somogyi-Nelson method [35,36]. One unit of mutanase activity (U) was defined as the amount of the enzyme hydrolyzing mutan to yield reducing sugars equivalent to $1 \mu \mathrm{mol}$ of glucose/min, and expressed as units per $\mathrm{mL}$ of culture $(\mathrm{U} / \mathrm{mL}) .1 \mathrm{U}$ corresponds to 16.67 nkat.

\subsection{Preparation of Dextranase-Treated Mutan (DTM) for Mutanase Activity Determination}

DTM was prepared (50 dextranase U/per g of native mutan, $\mathrm{pH} 6.0,37^{\circ} \mathrm{C}, 3 \times 24 \mathrm{~h}$ ) and used as a substrate for mutanase activity determination. Native mutan was synthesized from sucrose as described previously [7]. An analysis of the linkage structure of the native and the dextranase-treated mutans, as determined by ${ }^{1} \mathrm{H}-\mathrm{NMR}$, showed that they were mixed-linkage $\alpha-(1 \rightarrow 3)$ and $\alpha-(1 \rightarrow 6)$ biopolymers with a higher proportion of $\alpha-(1 \rightarrow 3)$ - than $\alpha-(1 \rightarrow 6)$-linkages, namely, 59.1 and $40.9 \mathrm{~mol} \%$ for the native mutan and 79.8 and $20.2 \mathrm{~mol} \%$ for DTM, respectively.

\subsection{Statistical Analysis}

Statistical analysis of data was performed on three replicates from each treatment. Standard deviations between the values obtained in each experiment for glucosidic linkage content and viscosity and optical rotation were less than 3\%, and those for mutanase activity were less than 5\%. Standard deviations were determined using Microsoft ${ }^{\circledR}$ Excel 2000 (Microsoft Corp., Redmond, WA, USA). The Pearson correlation coefficient $(\mathrm{R})$, the determination coefficient $\left(\mathrm{R}^{2}\right)$, and the linear regression $(\mathrm{y})$ were determined (using Microsoft ${ }^{\circledR}$ Excel 2000) to show the direction and strength of the relationship between the total percentage content of $\alpha-(1 \rightarrow 3)$-linkages in mutan chains (obtained under different conditions) and mutanase activities in the culture fluid of $T$. harzianum after induction by a particular inductor. Other methodological details are given in legends to Tables. 


\section{Conclusions}

In conclusion, the present study clearly reveals the great structural diversity of streptococcal mutans formed under different conditions by growing cultures and by their glucosyltransferases. Bacterial strain, kind of medium, and differential culture and environmental conditions affect the number of $\alpha$ - $(1 \rightarrow 3)$ - and $\alpha-(1 \rightarrow 6)$-linkages in the mutan molecule and their mutual proportion, which results in smaller or larger dissimilarities in cariogenic mutans. However, despite biosynthetic differences causing structural variation in the mutans, it did not matter which mutan structures were used to induce mutanase production. No correlation was found between the total percentage content of $\alpha-(1 \rightarrow 3)$-bonds in a glucan polymer and mutanase activity, but mutans with higher contents of $(1 \rightarrow 3)$-linked glucose had enhanced susceptibility to mutanolysis. It seems beneficial for prospective production of this valuable enzyme since it relieves the producer of the necessity of applying an inducer with a closely defined linkage structure.

\section{Acknowledgments}

This work was financially supported by the BW/BS/BiB/UMCS Research Programs.

\section{Conflict of Interest}

The authors declare no conflict of interest.

\section{References}

1. Russell, R.R.B. Bacterial Polysaccharides in Dental Plaque. In Bacterial Polysaccharides. Current Innovations and Future Trends; Ullrich, M., Ed.; Caister Academic Press: Norfolk, UK, 2009; pp. 143-156.

2. Banas, J.A.; Vickerman, M.M. Glucan-binding proteins of the oral streptococci. Crit. Rev. Oral Biol. Med. 2003, 14, 89-99.

3. Bowen, W.H.; Koo, H. Biology of Streptococcus mutans-derived glucosyltransferases: Role in extracellular matrix formation of cariogenic biofilms. Carbohydr. Res. 2011, 45, 69-86.

4. Colby, S.M.; Russell, R.R.B. Sugar metabolism by mutans streptococci. J. Appl. Microbiol. Symp. Suppl. 1997, 83, 80S-88S.

5. Pleszczyńska, M.; Marek-Kozaczuk, M.; Wiater, A.; Szczodrak, J. Paenibacillus strain MP-1: A new source of mutanase. Biotechnol. Lett. 2007, 29, 755-759.

6. Wiater, A.; Szczodrak, J.; Pleszczyńska, M.; Próchniak, K. Production and use of mutanase from Trichoderma harzianum for effective degradation of streptococcal mutans. Braz. J. Microbiol. 2005, 36, 137-146.

7. Wiater, A.; Szczodrak, J.; Pleszczyńska, M. Optimization of conditions for the efficient production of mutan in streptococcal cultures and post-culture liquids. Acta Biol. Hung. 2005, 56, $137-150$.

8. Kopec, L.K.; Vacca-Smith, A.M.; Bowen, W.H. Structural aspects of glucans formed in solution and on the surface of hydroxyapatite. Glycobiology 1997, 7, 929-934. 
9. Shimamura, A. Use of ${ }^{13} \mathrm{C}-\mathrm{NMR}$ spectroscopy for the quantitative estimation of 3-O- and 3,6-di$O$-substituted D-glucopyranosyl residues in $\alpha$-D-glucans formed by the D-glucosyltransferases of Streptococcus sobrinus. Carbohydr. Res. 1989, 185, 239-248.

10. Yui, T.; Goto, K.; Kawano, Y.; Ogawa, K. Molecular modeling study of highly branching $(1 \rightarrow 3)-$ $\alpha$-D-glucan, a model polysaccharide for cariogenic glucan, using the $N-H$ mapping method. Biosci. Biotechnol. Biochem. 2000, 64, 52-60.

11. Wiater, A.; Szczodrak, J.; Rogalski, J. Hydrolysis of mutan and prevention of its formation in streptococcal films by fungal $\alpha$-D-glucanases. Process Biochem. 2004, 39, 1481-1489.

12. Aires, C.P.; Koo, H.; Sassaki, G.L.; Iacomini, M.; Cury, J.A. A procedure for characterizing glucans synthesized by purified enzymes of cariogenic Streptococcus mutans. Int. J. Biol. Macromol. 2010, 46, 551-554.

13. Fukui, K.; Moriyama, T.; Miyake, Y.; Mizutani, K.; Tanaka, O. Purification and properties of glucosyltransferase responsible for water-insoluble glucan synthesis from Streptococcus mutans. Infect. Immun. 1982, 37, 1-9.

14. Furuta, T.; Koga, T.; Nisizawa, T.; Okahashi, N.; Hamada, S. Purification and characterization of glucosyltransferases from Streptococcus mutans 6715. J. Gen. Microbiol. 1985, 131, 285-293.

15. Guggenheim, B. Enzymatic hydrolysis and structure of water-insoluble glucan produced by glucosyltransferases from a strain of Streptococcus mutans. Helv. Odontol. Acta 1970, 14, 89-108.

16. Wiater, A.; Choma, A.; Szczodrak, J. Insoluble glucans synthesized by cariogenic streptococci: A structural study. J. Basic Microbiol. 1999, 39, 265-273.

17. Inoue, M.; Koga, T.; Sato, S.; Hamada, S. Synthesis of adherent insoluble glucan by the concerted action of the two glucosyltransferase components of Streptococcus mutans. FEBS Lett. 1982, 143, 101-104.

18. Koga, T.; Sato, S.; Yakushiji, T.; Inoue, M. Separation of insoluble and soluble glucan-synthesizing glucosyltransferases of Streptococcus mutans OMZ 176 (serotype d). FEMS Microbiol. Lett. 1983, 16, 127-130.

19. Ebisu, S.; Misaki, A. The structure of water-insoluble glucans of cariogenic Streptococcus mutans, formed in the absence and presence of dextranase. Carbohydr. Res. 1974, 38, 374-381.

20. Aires, C.P.; Tenuta, L.M.; Carbonero, E.R.; Sassaki, G.L.; Iacomini, M.; Cury, J.A. Structural characterization of exopolysaccharides from biofilm of a cariogenic streptococci. Carbohydr. Polym. 2011, 84, 1215-1220.

21. Côté, G.L.; Leathers, T.D. Insoluble glucans from planktonic and biofilm cultures of mutans of Leuconostoc mesenteroides NRRL B1355. Appl. Microbiol. Biotechnol. 2009, 82, 149-154.

22. Kopec, L.K.; Vacca-Smith, A.M.; Wunder, D.; Ng-Evans, L.; Bowen, W.H. Properties of Streptococcus sanguinis glucans formed under various conditions. Carbohydr. Res. 2001, 35, 67-74.

23. Nisizawa, T.; Imai, S.; Akada, H.; Hinoide, M.; Araya, S. Extracellular glucans produced by oral streptococci. Arch. Oral Biol. 1976, 21, 207-213.

24. Eifuku, H.; Yoshimitsu-Narita, A.; Sato, S.; Yakushiji, T.; Inoue, M. Production and partial characterization of the extracellular polysaccharides from oral Streptococcus salivarius. Carbohydr. Res. 1989, 194, 247-260.

25. Quivey, R.G.; Kriger, P.S. Raffinose-induced mutanase production from Trichoderma harzianum. FEMS Microbiol. Lett. 1993, 112, 307-312. 
26. Fuglsang, C.C.; Berka, R.M.; Wahleithner, J.A.; Kauppinen, S.; Shuster, J.R.; Rasmussen, G.; Halkier, T.; Dalbøge, H.; Henrissat, B. Biochemical analysis of recombinant fungal mutanases. J. Biol. Chem. 2000, 275, 2009-2018.

27. Hamada, S.; Torii, M. Effect of sucrose in culture media on the location of glucosyltransferase of Streptococcus mutans and cell adherence to glass surfaces. Infect. Immun. 1978, 20, 592-599.

28. Walker, G.J.; Brown, R.A.; Taylor, C. Activity of Streptococcus mutans $\alpha$-D-glucosyltransferases released under various grown condtions. J. Dent. Res. 1984, 63, 397-400.

29. Walker, G.J.; Morrey-Jones, J.G.; Svensson, S.; Taylor, C. Effect of Variation in Growth Conditins on the Activity of D-Glucosyltransferases and the Synthesis of $\alpha$-D-Glucans by Streptococcus mutans OMZ 176. In Glucosyltransferases, Glucans, Sucrose, and Dental Caries; Doyle, R.J., Ciardi, J.E., Eds.; DC-IRL Press: Washington, DC, USA, 1983; pp. 179-187.

30. Ceska, M.; Granath, K.; Norrman, B.; Guggenheim, B. Structural and enzymatic studies on glucans synthesized with glucosyltransferases of some strains of oral streptococci. Acta Chem. Scand. 1972, 26, 2223-2230.

31. Tsumuraya, Y.; Misaki, A. Structure of the water-insoluble $\alpha$-D-glucan of Streptococcus salivarius HHT. Carbohydr. Res. 1979, 74, 217-225.

32. Rees, D.A.; Scott, W.E. Polysaccharide conformation. Part VI. Computer model-building for linear and branched pyranoglycans. Correlations with biological function. Preliminary assessment of inter-residue forces in aqueous solution. Further interpretation of optical rotation in terms of chain conformation. J. Chem. Soc. B 1971, 469-479.

33. Mandels, M.; Parrish, F.W.; Reese, E.T. Sophorose as an inducer of cellulase in Trichoderma viride. J. Bacteriol. 1962, 83, 400-408.

34. Claridge, T.D.W. High-Resolution NMR Techniques in Organic Chemistry; Elsevier Science: Amsterdam, The Netherlands, 1999.

35. Nelson, N. A photometric adaptation of the Somogyi method for the determination of glucose. J. Biol. Chem. 1944, 153, 375-380.

36. Somogyi, M. A new reagent for the determination of sugars. J. Biol. Chem. 1945, 160, 61-68.

Sample Availability: Contact the authors.

(C) 2012 by the authors; licensee MDPI, Basel, Switzerland. This article is an open access article distributed under the terms and conditions of the Creative Commons Attribution license (http://creativecommons.org/licenses/by/3.0/). 